\title{
HYSTERESIS AND THE NAIRU: \\ THE CASE OF COUNTRIES \\ IN TRANSITION
}

\section{Gordana Marjanovic, Ljiljana Maksimovic, Nenad Stanisic*}

\begin{abstract}
:
The paper examines the hysteresis hypothesis in unemployment in the case of eight selected countries in transition, using the Kalman filter and testing whether the NAIRU time series are stationary. The empirical results show that the hysteresis effect is confirmed for the majority of the countries. Testing the influence of the inflation growth rate on the decline in the NAIRU and vice versa, performed using the panel regression with fixed effect, confirmed that the increase in inflation leads to decline in the NAIRU. The conclusion also suggests the existence of the impact of actual unemployment rate on the NAIRU, which may be affected by the change in aggregate demand.
\end{abstract}

Keywords: hysteresis, NAIRU, Kalman filter, inflation, unemployment.

JEL Classification: E24, E30, E50, C13

\section{Introduction}

Unemployment is a major problem, both in developed market economies, and countries that have gone through the transitional changes. Therefore, the goal of economic policy in modern economies is to reduce unemployment and thereby to avoid the rising inflationary pressures. In achieving this goal, the concept of Non - Accelerating Inflation Rate of Unemployment (NAIRU) and policy recommendations arising from this concept are of great importance.

NAIRU concept was first introduced by Modigliani and Papademos in 1975 (Snowdon, Vane, 2005, p. 402). Among economists, there are significant discrepancies in the definitions of the concepts of natural rate of unemployment (NRU), which was founded by Nobel Laureate M. Friedman, and the NAIRU. One group of scholars considers them identical (Gordon, Blanchard), while others argue that these are different concepts (Tobin, Stiglitz). The significant difference between the NRU and NAIRU relates to their different microeconomic basis. NRU concept implies market clearing, while the NAIRU refers to imperfect competition in labour and product markets. NAIRU is the unemployment rate with which the inflationary processes in excess demand markets are balanced with the disinflationary processes in excess supply markets. NAIRU can be defined under the different inflation rates, and at different rates of unemployment, and it responds to those conditions in the economy which allow stable rate of inflation. In contrast to the NRU, which implies that all markets are in equilibrium, NAIRU points out that not all markets have to be in balance.

* Gordana Marjanovic, Faculty of Economics, University of Kragujevac, Serbia;

Ljiljana Maksimovic, Faculty of Economics, University of Kragujevac, Serbia;

Nenad Stanisic, Faculty of Economics, University of Kragujevac, Serbia (nstanisic@kg.ac.rs). 
In addition to the discrepancies in the definition of the concept of NAIRU, in modern macroeconomic theory, there is considerable disagreement and controversy about the factors that determine the level and change of the NAIRU. One can distinguish two approaches to the factors that determine the NAIRU: exogenous and endogenous ones.

According to the exogenous approach, labour market characteristics, such as the bargaining power of trade unions, institutional arrangements, unemployment benefits, legislation, insider-outsider structures, etc. affect the NAIRU and increase the rigidity of the labour market. This approach emphasizes that the NAIRU is a result of these factors, which influence the wage increase and which in recent decades are often cited as the cause of rising unemployment in European countries. The exogenous approach finds the solution to this problem in labour market deregulation and unemployment benefits reduction (Sørensen \& Whitta-Jacobsen, 2010, p. 341).

According to the endogenous approach, the NAIRU is determined by the level of the actual unemployment rate, which is the basis of hysteresis theory (Blanchard and Summers, 1988). The hysteresis theory argues that the NAIRU is growing in the current period if in the previous period the actual unemployment rate was higher than the NAIRU, which can be represented as follows (Snowdon, Vane, 2005, p. 405):

$$
\mathrm{U}_{\mathrm{Nt}}=\mathrm{UNt}_{-1}+\alpha\left(\mathrm{U}_{\mathrm{t}-1}-\mathrm{U}_{\mathrm{Nt}-1}\right)+\mathrm{b}_{\mathrm{t}},
$$

Where $\mathrm{U}_{\mathrm{Nt}}-\mathrm{NAIRU}$ in $\mathrm{t}$ period,

$\mathrm{U}_{\mathrm{N} t-1}-\mathrm{NAIRU}$ from the previous period,

$\mathrm{U}_{\mathrm{t}-1}-$ actual unemployment rate from the previous period,

$b_{t} \quad-$ other variables which can influence the NAIRU (e.g. unemployment benefits).

If we assume that $b_{t}=0$, we get the following equation:

$$
\mathrm{U}_{\mathrm{Nt}}-\mathrm{U}_{\mathrm{Nt}-1}=\alpha\left(\mathrm{U}_{\mathrm{t}-1}-\mathrm{U}_{\mathrm{Nt}-1}\right) .
$$

We can see from this equation that $\mathrm{U}_{\mathrm{Nt}}>\mathrm{U}_{\mathrm{Nt}-1}$ if $\mathrm{Ut}_{-1}>\mathrm{U}_{\mathrm{Nt}-1}$. In other words, changing the actual unemployment rate acts as a magnet that «draws» the NAIRU in the same direction. The argument that aggregate demand does not affect the NAIRU can be acceptable in the short run but in the long run higher or lower economic activity leads to the changes in the NAIRU. Endogenous approach attaches more importance to economic policy whose effect on the reduction in the actual unemployment rate can result in decrease in the NAIRU.

In addition to the relationship between the NAIRU and the actual unemployment rate, the relationship between the movements of the NAIRU rate and changes in the inflation rate, which is represented by the Phillips curve, should be mentioned. The variant of expectations-augmented Phillips curve, which includes the concept of NAIRU, is based on the assumption that the inflation rate will be constant when the actual unemployment rate is equal to the NAIRU; it will increase when the actual unemployment falls below the NAIRU, and vice versa. In general terms, it can be represented as follows (Bozani, Drydakis, 2011, pp. 15-16):

$$
\pi_{\mathrm{t}}=\pi_{\mathrm{t}}^{\mathrm{e}}+\beta\left(\mathrm{U}_{\mathrm{t}-1}-\mathrm{U}_{\mathrm{Nt}}\right)+\delta \mathrm{z}_{\mathrm{t}}+\varepsilon_{\mathrm{t}} \quad \beta<0
$$


where $\pi_{t}$ is the actual rate of inflation in period $t ; \pi_{t}^{e}$ - the expected rate of inflation for period $t$, expected to be equal to the rate of inflation in period $t-1 ; \mathrm{U}_{\mathrm{t}-1}$ - unemployment rate in period $\mathrm{t}-1 ; \mathrm{U}_{\mathrm{Nt}}-\mathrm{NAIRU}$ in period $\mathrm{t}$, which may be constant but may change with structural changes in the economy; $\mathrm{z}_{\mathrm{t}}$ - a variable that refers to the supply shocks with ex-ante expected value of zero, and $\varepsilon_{t}$ - a variable that reflects the influence of all other factors. If $\pi_{\mathrm{t}}^{\mathrm{e}}$ is switched on the left side of the equation, we get:

$$
\Delta \pi_{\mathrm{t}}=\beta\left(\mathrm{U}_{\mathrm{t}-1}-\mathrm{U}_{\mathrm{Nt}}\right)+\delta \mathrm{z}_{\mathrm{t}}+\varepsilon_{\mathrm{t}} \quad \beta<0
$$

where $\Delta \pi_{t}$ is the difference between the rates of inflation in period $t$ and $t-1$. If the unemployment rate exhibits hysteresis effect, the impact of the inflation rate on the NAIRU can be observed through the changes in the real rate of unemployment (for example, monetary expansion increases inflation and reduces unemployment, which is pulling down the NAIRU rate).

Given the large number of factors that determine the NAIRU, this paper will explore the impact of the actual unemployment rate on the NAIRU, or hysteresis effect, as well as the effect of inflation rate on the NAIRU on the example of selected countries in transition. The paper starts with the following basic research hypotheses:

H1: actual unemployment rate affects the NAIRU-there is hysteresis effect

$\mathrm{H} 2$ : the increase in the inflation rate affects the decrease in the NAIRU and vice versa.

\section{Literature Review}

Monitoring of the hysteresis effect is the subject of many works. De-Chih Liu (2011) investigated the influence of hysteresis hypothesis on the opening and closing of job positions in the United States. The paper emphasizes the importance of demand management policy, where the fiscal and monetary policies stimulate aggregate demand, which in the short run has a positive impact on the opening of new job positions. However, the results of the research, using unit root tests based on the panel, show that the process of the opening and closing of job positions in the USA according to the structuralist paradigm (exogenous approach to determining the NAIRU), that the stabilization policy does not have a permanent effect on the opening and closing of job positions, and that the hysteresis hypothesis can be rejected.

Testing of the hysteresis hypothesis on the example of 14 OECD countries was performed by Liew, Chia, and Puah (2009), using several panel unit root tests. The results of the research show that hysteresis can be confirmed for most OECD countries, when tests are performed on individual countries. However, the hysteresis hypothesis in unemployment can be rejected for OECD countries overall, because unemployment rates tend to restore to long-run balance. This suggests that labour market institutions and stabilization policy successfully determine the unemployment rate at a sustainable level.

The research performed by Mohan, Kemegue, and Sjuib (2008) shows that the majority of studies, which were using the conventional unit root tests, supports the hysteresis hypothesis in OECD countries, and rejects the same hypothesis when investigating the labour market in the United States. This research, using the ADF Fisher, IPS, LLC, and Breitung panel unit root tests for individual regions in the United States, rejected the hysteresis hypothesis in unemployment. 
Stockhammer and Sturn (2008) investigate the hypothesis that the extent to which hysteresis occurs in the aftermath of recessions depends on monetary policy reactions in 19 OECD countries. The results suggest strong effects of monetary policy, but weak effects of labour market institutions. Those countries which more aggressively reduced their real interest rates in the vulnerable period of a recession experienced a much smaller increase in the NAIRU.

The presence of hysteresis in the euro area was examined by Loageay and Tober (2005) using the Kalman filter. The results of this research confirmed the presence of hysteresis effect, particularly in Germany. León-Ledesma (2002) analysed the presence of hysteresis in unemployment in the United States and the European Union. The results show that the hysteresis is confirmed in European countries and rejected in the United States.

Ball (2009) analysed unemployment rates in 20 developed countries, using the HP filter, and came to the conclusion that there is hysteresis effect and that monetary policies can affect unemployment.

Although the hysteresis effect is mostly analysed in developed economies, there is an increasing number of researches in the European transition countries. León-Ledesma and McAdam (2003) investigated the presence of hysteresis in 12 transition countries of Central and Eastern Europe, using the unit root tests on individual time series and on panel data, as well as Markov switching model. The analysis also included the impact of structural breaks on the formation of multiple equilibrium states, which occur as a result of shocks. They compared these results with the results of the aggregate data analysis for 15 European countries (EU-15), and came to the conclusion that maintaining equilibrium is faster in transition countries, but the transitions from one equilibrium state to another are more frequent than in the EU-15.

Camamero, Carrion-i-Silvestre, and Tamarit (2005) test for the hysteresis versus the natural rate hypothesis on the unemployment rates of the EU new members. They found that the application of the standard GLS-class of unit root tests confirms the hysteresis in the unemployment rates, but the opposite is true when allowing for the presence of up to two structural breaks in unit root testing.

Cuestas and Ordonez (2011) show that for five CEE countries (Hungary, Latvia, Poland and Slovenia, and the Slovak Republic) unemployment dynamics appears to be well described as a stationary process around highly persistent structural changes.

Cuestas, Gil-Alana, and Staehr (2011) analyzed the dynamics of the unemployment rate in the eight CEE countries which joined the EU in 2004. They found that the unemployment rate is not stationary in most of the sample countries and that shocks are highly persistent, implying a slow rate of convergence to the natural rate of unemployment. The unemployment rate is least persistent in Hungary and Slovenia, more persistent in the Czech Republic, Slovakia and the Baltic States and extremely persistent in Poland.

Gozgor (2013) tested the hysteresis effect in ten CEE countries, and provide significant empirical support for the existence of persistence in unemployment rates, and the hysteresis hypothesis. 


\section{Model}

In order to test the hypothesis defined in the introduction, two things have to be done. First, we need to determine the NAIRU from the actual unemployment data series, and second, we have to test the relation between NAIRU and inflation rate. Following previous considerations, the rate of unemployment can be viewed as the sum of three components: frictional, structural, and cyclical unemployment, where the first two components are parts of the NAIRU:

$$
\mathrm{U}_{\mathrm{t}}=\mathrm{U}_{\mathrm{Nt}}+\mathrm{U}_{\mathrm{cyc} \mathrm{t}}
$$

where $U_{t}$ is the observed actual unemployment rate in time $t, \mathrm{U}_{\mathrm{N}}$ is the NAIRU, and $\mathrm{U}_{\text {cyc }}$ is the rate of cyclical unemployment.

In order to specify the empirical model which will detect the unobserved components $\left(U_{\mathrm{N}}\right.$ and $\left.\mathrm{U}_{\mathrm{cyc}}\right)$ from the easily accessible actual rate of unemployment, the assumptions have to be made regarding the nature of the movement of the components $\mathrm{U}_{\mathrm{N}}$ and $\mathrm{U}_{\mathrm{yc}}^{\mathrm{c}}$.

Following the seminal work of Blanchard and Quah (1989), the fluctuations in unemployment (as well as in output) result from two types of shocks, supply shocks and demand shocks. Supply shocks (as changes in technology, demographic changes, etc.) alter the position of long-run aggregate supply curve, and change the level of full employment and potential output. On the other hand, the demand shocks (as changes in monetary and fiscal policy, changes in consumption, both foreign and domestic, etc.) do not influence the long run full-employment level of output. Thus, the main distinctions between these two types of disturbances are made regarding the lasting of their effects. While the supply shocks have permanent, long-lasting effects, the demand shocks have temporary influence on full-employment level of output.

Based on these considerations, widely accepted in the literature, it can be assumed that the NAIRU follows a random walk (see Gordon, 1997 and 1998; Laubach, 2001; Apel and Jansson, 1999a, 1999b; Claar, 2005):

$$
\mathrm{U}_{\mathrm{Nt}}=\mathrm{U}_{\mathrm{N} \mathrm{t}-1}+\varepsilon_{\mathrm{t}}
$$

where $\varepsilon_{\mathrm{t}}$ is independently distributed error term with

$$
\varepsilon_{\mathrm{t}} \sim \mathrm{N}\left(0, \sigma_{\varepsilon}^{2}\right)
$$

When the standard deviation $\sigma_{\varepsilon}=0$, then $\mathrm{U}^{\mathrm{N}}$ is constant over time. When $\sigma_{\varepsilon} \neq 0$, the model allows the NAIRU to vary by an amount $\sigma_{\varepsilon}$ in each period.

Regarding the fluctuation in other component of actual rate of unemployment, the cyclical unemployment $\mathrm{U}^{\mathrm{cyc}}$, following Apel and Jansson (1999a, 1999b), and Claar (2005), we assume that it exhibits first-order serial correlation:

$$
\mathrm{U}_{\text {cyct }}=\rho \mathrm{U}_{\text {cyct- } 1}+\varepsilon^{\prime}{ }_{\mathrm{t}}
$$

where $\rho$ is between zero and one, and where $\varepsilon_{t}^{\prime}$ is independently distributed error term with

$$
\varepsilon_{\mathrm{t}}^{\prime} \sim \mathrm{N}\left(0, \sigma_{\varepsilon^{\prime}}{ }^{2}\right)
$$


Presented model, with the use of two independently distributed shocks, one for NAIRU and the other for cyclical rate of unemployment, clearly distinguishes two types of shocks, supply shocks, which alter the NAIRU, and demand shocks which cannot alter the NAIRU. Detailed specification of the Kalman filter model is presented in the following section of the paper.

The second part of the model consists of the statistical test of relation between the NAIRU and inflation rate. We have employed the panel data regression model in this paper. A panel has the form $\mathrm{X}_{i t}$, where $\mathrm{X}$ is a vector of observed variables (NAIRU and inflation rate), $i$ goes from 1 to $\mathrm{N}$, where $\mathrm{N}$ is the number of observed countries, and $t$ covers the period from 2000 to 2012 .

A fixed effect panel data regression model can be written as:

$$
\begin{gathered}
\mathrm{U}_{\mathrm{Nit}}=\alpha+\beta \mathrm{CPI}_{\mathrm{it}}+\mathrm{u}_{\mathrm{it}} \\
\mathrm{U}_{\mathrm{it}}=\mu_{\mathrm{i}}+v_{\mathrm{it}}
\end{gathered}
$$

Where $\mathrm{U}_{\mathrm{N}}$ is the NAIRU, CPI is the consumer price index and $\mu_{\mathrm{i}}$ is individual-specific, time-invariant effect.

The series of data used in this study is the quarterly unemployment rate and inflation rate of eight European transitional economies, ranging from 2000 to 2012. The countries' sample consists of five Central European economies (Poland, Hungary, the Czech Republic, Slovakia, Slovenia, all member states of the EU since 2004), and two East European economies (Bulgaria and Romania, members of the EU since 2007), and Croatia (a member of the EU since 2013). Data are taken from Eurostat.

\section{Kalman Filter Method}

Once the model is specified, the appropriate research method should be employed. Various methods were used in the literature for estimating the natural rate of unemployment (as well as the NAIRU), ranging from simple fitting the trend in the time series of unemployment to using structural models of labour market. Apel and Jansson (1999a) surveyed the common ones: Hodrick-Prescott filter, the so-called multivariate filter of Laxton and Tetlow, methods based on structural vector autoregressive models, and the so called STM (Structural Time-Series Models) or UC (Unobserved Components) models, and concluded that the last mentioned method has some significant advantages over others. Therefore, we employ the UC method in this paper, specifically the Kalman filter algorithm. The intuition behind this method is as follows: specified model relates the unobservable variable (NAIRU in this case) to observable variable - actual unemployment. A recursive Kalman-filter algorithm can be applied to the so called state-space representation of the model, in order to find a sequence of optimal predictions of the observable variable for a given set of coefficients and sequence of the unobservable one (Apel and Jansson, 1999a). By comparing these predictions to the actual values of unemployment, a specific series of forecast errors are used in a maximum likelihood routine to find the optimal set of parameters and the corresponding estimates of the natural rate of employment. 
In order to apply the Kalman filter procedure, the system must be written in a state space form, with a measurement equation and a transition equation:

$$
\begin{aligned}
& Z_{t}=H X_{t}+\eta_{t} \text { (measurement equation) } \\
& X_{t}=A X_{t-1}+B U_{t}+\omega_{t} \text { (transition equation) }
\end{aligned}
$$

where $\mathrm{Z}$ is a vector of observed variables, $\mathrm{X}$ is a vector of unobserved variables, and $\mathrm{U}$ is a vector of controlled variables. Matrixes $\mathrm{H}, \mathrm{A}$, and $\mathrm{B}$ contain parameters that correspond to $X_{t}, X_{t-1}$, and $U_{t}$, respectively. Terms $\eta_{t}$ and $\omega_{t}$ are independently distributed error terms.

Our model, developed in the previous section, can be written in the state space form as follows. The equation (1) may be equivalently expressed as:

$$
\mathrm{U}_{\mathrm{t}}=\mathrm{HX}_{\mathrm{t}}, \mathrm{t}=1, \ldots, \mathrm{T}
$$

where $\mathrm{Xt}$ is the $2 \mathrm{x} 1$ vector of the unobserved variables $\mathrm{U}^{\mathrm{N}}$ and $\mathrm{U}^{\mathrm{cyc}}$. $\mathrm{H}$ is a fixed $1 \mathrm{x} 2$ vector that, in this model, contains ones for its elements. This is the measurement equation that relates the unobserved variables to the observable variable Ut.

Equations (2)-(5) can be written as transition equations as follows:

$$
X_{t}=A X_{t-1}+\omega_{t}
$$

where $A$ is a matrix with 1 and $\rho$ on the main diagonal, and $\omega_{t}=\left(\varepsilon_{t}, \varepsilon_{t}^{\prime}\right)$.

Following Claar (2005), our model does not contain error term $\eta_{t}$ in the measurement equation. Claar (2005) justifies this by the fact that "the unemployment rate is measured reasonably well and, more importantly, it is measured in the same manner every period. Secondly, adding an additional term to the unemployment rate equation would exacerbate the problem of distilling the natural rate of unemployment (the NAIRU in this case) from the single unemployment rate series by introducing a third source of fluctuation in the unemployment rate". The model also does not contain matrix of controlled variables $U_{t}$ in the transition equation, which is a common feature of models in relevant studies.

Before running the Kalman filter, the unknown parameters in the state space model $\left(\rho, \sigma_{\varepsilon}{ }^{2}, \sigma_{\varepsilon}{ }^{2}\right)$ should be estimated. The values of the variance of the error terms are estimated in the maximum likelihood process, while we have used a variety of starting values for $\rho$ that are consistent with a business cycle half-life ranging from 6 to 48 months, which is a duration of temporarily disturbances to unemployment determined in Blanchard and Quah (1989), as well as in many other studies.

Another issue is to estimate the initial values of unobserved variables, which is necessary when the time series are non-stationary, as it is the case when the NAIRU is assumed to evolve as a random walk, like in our model. There are two traditional approaches to this problem. In the first one, the initial value of the NAIRU is considered to be fixed, while in the second approach, the initial value is presumed to be random, and a diffuse prior for the distribution is assumed. The second approach is used in this paper. More about the Kalman filter procedures and estimation techniques can be found in Claar (2005) and Turner, et al. (2001). 


\section{Results}

Using the Kalman filter, the actual unemployment rates in the observed countries are decomposed into the NAIRU and cyclical component. The obtained NAIRU is shown in the Appendix. In the first quarter of 2000 (first observed quarter), Hungary had the lowest NAIRU (5.14), followed by Slovenia (6.47), Romania (7.01), and the Czech Republic (8.48). In contrast to this group of countries, there is a group of countries with high NAIRU in the first observed quarter, consisting of Bulgaria (18.46), Poland (19.78), and Slovakia (20.06). As a result of the successful transition reform and accession to the $\mathrm{EU}$, there was a significant decrease in the NAIRU in all surveyed countries (except for Hungary) by the end of the period (2012Q4). In the last quarter of 2012, the Czech Republic had the lowest NAIRU (6.53), followed by Romania (6.97), Poland (7.72), Slovenia (8.10), and Bulgaria (9.69). The three countries which at the end of the period had the NAIRU over $10 \%$ are: Croatia (13.10), Slovakia (12.56), and Hungary (11.55). Higher NAIRU in the last compared to the first quarter (2012Q4 in contrast to 2000Q1) was observed only in the case of Hungary, while all other countries had a decline in the NAIRU in the observed period.

Bearing in mind that the hysteresis effect involves a change in the NAIRU over time, the existence of hysteresis can be tested by examining the existence of statistically significant deterministic or stochastic trend in the obtained series of the NAIRU. The results of testing the existence of the trend are presented in Table 1. There is statistically significant trend in six countries, of which in five cases there is a negative one (Bulgaria, Poland, Romania, Slovakia, and the Czech Republic), while in the case of Hungary there is a positive trend, i.e. the growth in NAIRU during the period (2000-2012). The trend is not statistically significant in the case of Slovenia and Croatia; their NAIRU does not show a tendency towards statistical significance over the time.

Table 1 | Analysis of the NAIRU trend

\begin{tabular}{|l|c|c|}
\hline & Trend coefficient & R-squared \\
\hline Bulgaria & $-0.1838^{* * *}$ & 0.8229 \\
\hline Hungary & $0.1287^{* * *}$ & 0.9816 \\
\hline Poland & $-0.2579^{* * *}$ & 0.9938 \\
\hline Romania & $-0.0012^{* *}$ & 0.8837 \\
\hline Slovenia & 0.0267 & 0.4779 \\
\hline Slovakia & $-0.1577^{* * *}$ & 0.9391 \\
\hline Croatia & -0.0287 & 0.2010 \\
\hline Czech Republic & $-0.0416^{* * *}$ & 0.8964 \\
\hline
\end{tabular}

Source: own calculation 
The existence of a hysteresis effect can alternatively be proved by testing whether the NAIRU time series are stationary. As stated in the section model, the assumption is that the NAIRU has a random walk, i.e. it is non-stationary series. Table 2 presents the results of Kwiatowski-Phillips-Schmidt-Shin (KPSS) test of whether the NAIRU time series are stationary. In all eight cases, one can reject the hypothesis on whether the NAIRU time series are stationary, i.e. conducted KPSS test confirms the existence of hysteresis effect on a sample of observed transition countries.

Table 2 | The Results of the KPSS Test on whether the NAIRU Is Stationary

\begin{tabular}{|l|l|}
\hline & KPSS test statistics* \\
\hline Bulgaria & $0.2522^{* * *}$ \\
\hline Hungary & $0.2519^{* * *}$ \\
\hline Poland & $0.1302^{*}$ \\
\hline Romania & $0.1528^{* *}$ \\
\hline Slovenia & $0.2503^{* *}$ \\
\hline Slovakia & $0.2461^{* * *}$ \\
\hline Croatia & $0.2225^{* * *}$ \\
\hline Czech Republic & $0.2462^{* * *}$ \\
\hline
\end{tabular}

Source: own calculation

*Bandwidth: 5 (Newey-West automatic) using Bartlett kernel note: ${ }^{* *}-0.01^{* *}-0.05^{*}-0.1$

The result of testing the hysteresis effect existence is consistent with previous studies carried out by Liew, Chia and Puah (2009) which confirmed the existence of this phenomenon in the case of OECD countries individually. It is also consistent with the studies that have confirmed the presence of hysteresis in developed countries, carried out by Loageay and Tober (2005), then Ball (2009), and León-Ledesma (2002).

Testing other research hypothesis - the hypothesis that an increase in the inflation rate affects the decline in the NAIRU and vice versa was performed using the method of panel regressions with fixed effects. Stationarity of the time series is provided using the Trend Stationary Process (TSP), in order to eliminate the deterministic trend, and using the Difference-Stationary Process (DSP), to eliminate the stochastic trend. Since the regression model on the first differences showed the existence of autocorrelation, i.e. statistical errors were positively correlated with statistical errors from previous periods (low value of the Durbin-Watson statistic), the first-order auto-regression model is defined (first order AR - AR (1)). The dependent variable was the first difference of the previously estimated NAIRU, while the first difference of consumer price index (CPI) is an independent variable of the regression equation. Panel regression results are presented in Table 3. 
Table 3 | Panel Regression Results of the NAIRU Dependency on CPI

\begin{tabular}{|l|c|c|c|c|}
\hline \multicolumn{5}{|c|}{ Total panel observations: 10x52=512 } \\
\hline Variable & Coefficient & Std. Error & t-Statistic & Prob. \\
\hline C & 10.15348 & 0.131172 & 77.40558 & 0.0000 \\
\hline D(CPI) & -0.003512 & 0.021700 & -2.926778 & 0.0036 \\
\cline { 1 - 2 } R-squared & 0.765385 & & & \\
\cline { 1 - 2 } $\begin{array}{l}\text { Adjusted } \\
\text { R-squared }\end{array}$ & 0.733581 & & & \\
\cline { 1 - 2 } F-statistic & 24.06612 & & & \\
\cline { 1 - 2 } Prob (F-statistic) & 0.000000 & DW stat. & 1.676803 & \\
\cline { 1 - 3 }
\end{tabular}

Source: own calculation

The resulting regression equation confirms that inflation rate has a statistically significant effect on the NAIRU in the group of observed countries, i.e. monetary policy manifests effects on the NAIRU movement in a way that the increase in the inflation rate leads to the decrease in the NAIRU.

\section{Conclusion}

Because of the great importance, a number of theoretical and empirical literatures have evolved concerning hysteresis theory and the concept of the NAIRU. Hysteresis influences that unemployment dynamics is a non-stationary process, i.e. there is no unique level unemployment seeks in the long run. The paper tests the existence of hysteresis effect and the influence of inflation trends on the NAIRU on the example of eight countries in transition.

The NAIRU is determined using the Kalman filter, and the results of testing whether its series are stationary demonstrate that in the case of all the eight countries there is hysteresis effect. A similar result was obtained by testing the existence of a trend in the series of NAIRU when hysteresis was confirmed in the case of six countries of which in five cases there was decrease in the NAIRU over time (in the case of Bulgaria, Poland, Romania, Slovakia, and the Czech Republic), and increase in the case of Hungary in the period between 2000 and 2012. The trend is not statistically significant in the case of Slovenia and Croatia; their NAIRU does not show a tendency towards statistical significance over time.

Analysis of the impact of inflationary tendencies on the NAIRU was conducted using the panel regression analysis, and the results confirm the existence of a small but statistically significant effect of change in the consumer price index on the NAIRU. This means that the policy of demand management, i.e. monetary policy, can affect the movement of unemployment and inflation. Limitation of the model is that the results were obtained by testing only the impact of inflation on the NAIRU, without taking into consideration a number of factors concerning both demand and supply. 


\section{References}

Apel, M., Jansson, P. (1999a), "System Estimates of Potential Output and the NAIRU." Empirical Economics, Vol. 24, No. 3, pp. 373-88, http://dx.doi.org/10.1007/s001810050061

Apel, M., Jansson, P. (1999b), "A Theory-Consistent System Approach for Estimating Potential Output and the NAIRU." Economics Letters, Vol. 64, No. 3, pp. 271-5, http://dx.doi. org/10.1016/S0165-1765(99)00111-1

Ball, L. (2009), "Hysteresis and Unemployment: Old and New Evidence." NBER Working Paper No. 14818.

Blanchard, O., Quah, D. (1989), "The Dynamic Effects of Aggregate Demand and Supply Disturbances." American Economic Review, Vol. 79, No. 4, pp. 655-673.

Blanchard, O., Summers, L. (1986), "Hysteresis and the European Unemployment Problem." NBER Macroeconomics Annual, No. 1.

Bozani, V., Drydakis, N. (2011), Studying the NAIRU and Its Implications, the Institute for the Study of Labor Discussion Paper, No. 6079.

Camarero, M., Carrion-Silvestre, J. L., Tamarit, C. (2005), “Unemployment Dynamics and NAIRU Estimates for CEECs: A Univariate Approach." Working Papers in Economics, Facultat d'Economia i Empresa, Universitat de Barcelona.

Claar, V. (2005), "A Kalman Filter Approach to Estimating the Natural Rate of Unemployment." Proceedings of Rijeka School of Economics: Journal of Economics and Business, Vol. 23, No. 1, pp. 1-24.

Cuestas, J. C., Gil-Alana, L. A. and Staehr, K. (2011), “A Further Investigation of Unemployment Persistence in European Transition Economies." Journal of Comparative Economics, Vol. 39, No. 4, pp. 514-532, http://dx.doi.org/10.1016/j.jce.2011.09.002

Cuestas, J. C., Ordonez, J. (2011), "Unemployment and Common Smooth Transition Trends in Central and Eastern European Countries." Economic Issues, Vol. 16, No. 2, pp. 39-52.

De-Chih, L. (2011), “Hysteresis Hypothesis in Job Creation and Destruction: Evidence from the U.S." Annals of Economics and Finance, Vol. 12, No. 2, pp. 389-409.

Gordon, R. J. (1997), "The Time-Varying NAIRU and Its Implications for Economic Policy." Journal of Economic Perspectives, Vol. 11, No.1, pp. 11-32, http://dx.doi.org/10.1257/ jep.11.1.11

Gordon, R. J. (1998), “Foundations of the Goldilocks Economy: Supply Shocks and the Time-Varying NAIRU." Brookings Papers on Economic Activity, Vol. 29, No. 2, pp. 297-346.

Gozgor, G. (2013), "Testing Unemployment Persistence in Central and Eastern European Countries." International Journal of Economics \& Financial Issues, Vol. 3, No. 3, pp. 694-700.

Laubach, T. (2001), "Measuring the NAIRU: Evidence from Seven Economies." Review of Economic and Statistics, Vol. 83, No. 2, pp. 218-31, http://dx.doi. org/10.1162/00346530151143761

León-Ledesma, M. (2002), “Unemloyment Hysteresis in the US and the EU: A Panel Data Approach." Bulletin of Economic Research, Vol. 54, No. 2, pp. 95-105.

León-Ledesma, M., Mc Adam, P. (2003), “Unemployment, Hysteresis and Transition.” European Central Bank, Working Paper No. 234.

Liew, V. K., Chia, R. C., Puah, C. H. (2009), “Does Hysteresis in Unemployment Occur in OECD Countries? Evidence from Parametric and Non-Parametric Panel Unit Roots Tests." MPRA Papers No. 9915. 
Loageay, C., Tober, S. (2005), Hysteresis and NAIRU in the Euro Area, Macroeconomic Policy Institute, Working Paper No. 4/2005.

Mohan, R., Kemegue, F., Sjuib, F. (2008), "Hysteresis In Unemployment: Panel Unit Roots Tests Using State Level Data." Journal of Business \& Economics Research, Vol. 6, No. 2, pp. 53-60.

Snowdon, B., Vane, H. R. (2005), Modern Macroeconomics: Its Origins, Development and Current State. Edward Elgar Publishing.

Sørensen, P. B., Whitta-Jacobsen, H. J. (2010), Introducing Advanced Macroeconomics: Growth and Business Cycles. 2th Edition, McGraw-Hill Education.

Stockhammer, E., Sturn, S. (2008), "The Impact of Monetary Policy on Unemployment Hysteresis." IMK Working Paper, 15-2008.

Turner, D., Boone, L., Giorno, C., Meacci, M., Rae, D., Richardson, P. (2001), “Estimating the Structural Rate of Unemployment for the OECD Countries." OECD Economic Studies, No. 33, 2001/II.

\section{Appendix}

\section{NAIRU for selected economies}

\begin{tabular}{|l|c|c|c|c|c|c|c|c|}
\hline & Bulgaria & Hungary & Poland & Romania & Slovenia & Slovakia & Croatia & $\begin{array}{c}\text { Czech } \\
\text { Republic }\end{array}$ \\
\hline 2000Q1 & 18.46833 & 5.14109 & 19.78095 & 7.015875 & 6.479235 & 20.06829 & & 8.486852 \\
\hline 2000Q2 & 18.12117 & 5.211158 & 19.61956 & 7.01588 & 6.451056 & 19.85564 & & 8.420142 \\
\hline 2000Q3 & 17.77375 & 5.281327 & 19.45788 & 7.015881 & 6.422899 & 19.64288 & & 8.353474 \\
\hline 2000Q4 & 17.42566 & 5.351781 & 19.29539 & 7.015872 & 6.394839 & 19.42988 & & 8.28692 \\
\hline 2001Q1 & 17.07644 & 5.422761 & 19.13132 & 7.015844 & 6.366976 & 19.21643 & & 8.220556 \\
\hline $2001 Q 2$ & 16.7257 & 5.494546 & 18.96476 & 7.01579 & 6.339397 & 19.0023 & & 8.154459 \\
\hline $2001 Q 3$ & 16.37312 & 5.567434 & 18.79465 & 7.015697 & 6.31217 & 18.78725 & & 8.088695 \\
\hline $2001 Q 4$ & 16.01862 & 5.641729 & 18.61989 & 7.015545 & 6.28534 & 18.57112 & & 8.023325 \\
\hline $2002 Q 1$ & 15.66235 & 5.717734 & 18.43936 & 7.015311 & 6.258931 & 18.35374 & 14.10842 & 7.958411 \\
\hline $2002 Q 2$ & 15.30465 & 5.795738 & 18.25195 & 7.014969 & 6.232994 & 18.13502 & 13.95149 & 7.893999 \\
\hline $2002 Q 3$ & 14.94615 & 5.876018 & 18.05666 & 7.014501 & 6.207605 & 17.91495 & 13.79461 & 7.830096 \\
\hline $2002 Q 4$ & 14.58768 & 5.958828 & 17.85259 & 7.013896 & 6.182837 & 17.69352 & 13.63788 & 7.766662 \\
\hline $2003 Q 1$ & 14.23029 & 6.044405 & 17.63899 & 7.013149 & 6.158764 & 17.47081 & 13.48152 & 7.703615 \\
\hline $2003 Q 2$ & 13.87521 & 6.132966 & 17.41528 & 7.01225 & 6.135465 & 17.24695 & 13.3258 & 7.640846 \\
\hline $2003 Q 3$ & 13.52369 & 6.224706 & 17.18106 & 7.011189 & 6.113061 & 17.02212 & 13.171 & 7.578223 \\
\hline $2003 Q 4$ & 13.17704 & 6.319796 & 16.93605 & 7.00995 & 6.091714 & 16.79649 & 13.01745 & 7.515618 \\
\hline $2004 Q 1$ & 12.83653 & 6.41837 & 16.68018 & 7.008516 & 6.071638 & 16.57027 & 12.86559 & 7.452934 \\
\hline $2004 Q 2$ & 12.50339 & 6.52052 & 16.41357 & 7.006873 & 6.053074 & 16.34374 & 12.71599 & 7.390122 \\
\hline $2004 Q 3$ & 12.17884 & 6.626295 & 16.13655 & 7.005017 & 6.036291 & 16.11737 & 12.56921 & 7.327195 \\
\hline $2004 Q 4$ & 11.8641 & 6.735699 & 15.84969 & 7.002958 & 6.021578 & 15.89176 & 12.4259 & 7.264238 \\
\hline $2005 Q 1$ & 11.56033 & 6.848709 & 15.55373 & 7.000714 & 6.009234 & 15.66767 & 12.28685 & 7.201395 \\
\hline $2005 Q 2$ & 11.2687 & 6.965278 & 15.24957 & 6.998314 & 5.999576 & 15.44596 & 12.15289 & 7.138875 \\
\hline
\end{tabular}




\begin{tabular}{|c|c|c|c|c|c|c|c|c|}
\hline 2005Q3 & 10.99031 & 7.085347 & 14.93832 & 6.995791 & 5.992958 & 15.22762 & 12.02491 & 7.076945 \\
\hline 2005Q4 & 10.72619 & 7.208876 & 4.62132 & 6.993185 & 5.989739 & 15.01368 & 11.90384 & 7.015929 \\
\hline 2006Q1 & 10.4773 & 7.335844 & 14.30007 & 6.990533 & 5.990319 & 14.80525 & 11.79067 & 6.956202 \\
\hline 2006Q2 & 10.24452 & 7.466245 & 13.97628 & 6.987869 & 5.995172 & 14.6035 & 11.68642 & 6.898194 \\
\hline 2006Q3 & 10.02865 & 7.600078 & 13.65172 & 6.985229 & 6.004804 & 14.40956 & 11.59207 & 6.84239 \\
\hline 2006Q4 & 9.830421 & 7.737336 & 13.3282 & 6.982649 & 6.019737 & 14.22452 & 11.50859 & 6.789294 \\
\hline 2007Q1 & 9.650491 & 7.878012 & 13.00752 & 6.980171 & 6.040477 & 14.04936 & 11.43698 & 6.739427 \\
\hline 2007Q2 & 9.489423 & 8.022084 & 12.69139 & 6.977839 & 6.067488 & 13.88495 & 11.37817 & 6.693294 \\
\hline 2007Q3 & 9.347638 & 8.169474 & 12.38139 & 6.975692 & 6.101184 & 13.73195 & 11.33297 & 6.651333 \\
\hline 2007Q4 & 9.225382 & 8.320049 & 12.07889 & 6.973769 & 6.141895 & 13.59088 & 11.30195 & 6.613894 \\
\hline 2008Q1 & 9.122734 & 8.47362 & 11.78506 & 6.972097 & 6.18985 & 13.46208 & 11.28544 & 6.581224 \\
\hline 2008Q2 & 9.039561 & 8.629965 & 11.5008 & 6.970699 & 6.245168 & 13.34568 & 11.2837 & 6.553452 \\
\hline $2008 Q 3$ & 8.975519 & 8.788799 & 11.22674 & 6.969584 & 6.307867 & 13.24161 & 11.29685 & 6.530557 \\
\hline $2008 Q 4$ & 8.930041 & 8.949773 & 10.96318 & 6.968752 & 6.377834 & 13.14956 & 11.32478 & 6.512365 \\
\hline 2009Q1 & 8.902312 & 9.112469 & 10.71014 & 6.968191 & 6.454819 & 13.06894 & 11.36717 & 6.498547 \\
\hline $2009 Q 2$ & 8.891263 & 9.276412 & 10.46736 & 6.967875 & 6.53842 & 12.99887 & 11.42346 & 6.488638 \\
\hline $2009 Q 3$ & 8.895617 & 9.441123 & 10.23433 & 6.967774 & 6.628127 & 12.93826 & 11.49294 & 6.4821 \\
\hline 2009Q4 & 8.913918 & 9.606162 & 10.01039 & 6.967853 & 6.723386 & 12.88591 & 11.57471 & 6.478394 \\
\hline $2010 \mathrm{Q} 1$ & 8.944593 & 9.77116 & 9.79474 & 6.96808 & 6.823626 & 12.84061 & 11.66773 & 6.477038 \\
\hline 2010Q2 & 8.986009 & 9.935827 & 9.586494 & 6.968423 & 6.928249 & 12.80125 & 11.77083 & 6.47761 \\
\hline $2010 Q 3$ & 9.036561 & 10.09997 & 9.384763 & 6.968857 & 7.036652 & 12.76683 & 11.88274 & 6.479776 \\
\hline 2010Q4 & 9.094714 & 10.26349 & 9.188659 & 6.96936 & 7.148267 & 12.73649 & 12.00225 & 6.483254 \\
\hline 2011Q1 & 9.159026 & 10.42637 & 8.997304 & 6.96991 & 7.262544 & 12.7095 & 12.12816 & 6.487807 \\
\hline 2011Q2 & 9.228209 & 10.58864 & 8.809847 & 6.97049 & 7.378972 & 12.68518 & 12.25931 & 6.493232 \\
\hline $2011 Q 3$ & 9.301118 & 10.75036 & 8.625466 & 6.971084 & 7.497096 & 12.66297 & 12.39462 & 6.499354 \\
\hline 2011Q4 & 9.376743 & 10.91163 & 8.443386 & 6.97168 & 7.616506 & 12.6423 & 12.5331 & 6.506026 \\
\hline $2012 Q 1$ & 9.4542 & 11.07256 & 8.262907 & 6.972271 & 7.736833 & 12.6227 & 12.67384 & 6.513107 \\
\hline $2012 Q 2$ & 9.532759 & 11.23325 & 8.083437 & 6.972856 & 7.857778 & 12.60379 & 12.81601 & 6.520459 \\
\hline $2012 Q 3$ & 9.611867 & 11.39382 & 7.904497 & 6.973436 & 7.97907 & 12.58524 & 12.95897 & 6.527967 \\
\hline 2012Q4 & 9.691156 & 11.55435 & 7.725744 & 6.974013 & 8.100488 & 12.56681 & 13.10221 & 6.535535 \\
\hline
\end{tabular}

Source: Authors' calculation based on Kalman filter method applied on actual unemployment rates (Eurostat database) 